\title{
CARL SCHMITT Y EL ESTADO DE EMERGENCIA ECONÓMICO
}

\section{CARL SCHMITT AND THE ECONOMIC STATE OF EMERGENCY}

\author{
Gilberto Bercovici \\ Universidade de São Paulo
}

\begin{abstract}
Sumario: I. INTRODUCCIÓN .- II. UNIDAD POLÍTICA Y ESTADO PLURALISTA .III. EL PRESIDENTE DEL REICH Y EL ESTADO DE EMERGENCIA ECONÓMICO .- IV. EL ESTADO TOTAL.- V. ESTADO FUERTE EN UNA ECONOMÍA LIBRE
\end{abstract}

Resumen: El artículo aborda el discurso de Carl Schmitt para justificar el estado de emergencia económico em la República de Weimar y su propuesta de defender un Estado fuerte en una economia libre como una forma de restaurar la unidad política alemana.

\begin{abstract}
The article analyses the discourse Carl Schmitt built in order to justify the economic state of emergency in the Weimar Republic, along with his proposal to defend a strong State in a free economy as a means to restore the German political unity.
\end{abstract}

Palabras Clave: Estado de Emergencia Económico - Carl Schmitt - Estado Total - Unidad Política - Constitución de Weimar

Key Words: Economic State of Emergency- Carl Schmitt - Total State - Political Unity - Weimar Constitution

\section{INTRODUCCIÓN}

El estado de excepción en Alemania fue consagrado por el célebre artículo 48 de la constitución de Weimar. El artículo 48 instituyó un estado de excepción flexible y desformalizado, rompiendo con la tradición liberal, fruto de la reacción a las crisis politicas y sociales de 1918-19191, hecho que lo diferenció de medidas de excepción más tradicionales, como la ley habilitante (Ermächtigungsgesetz). Una ley habilitante trata de competencias del gabinete, sin afectar los poderes

1 Para el debate sobre el artículo 48 de la constitución de Weimar, consulte Carl Schmitt, "Legalität und Legitimität", en Carl Schmitt, Verfassungsrechtliche Aufsätze aus den Jahren $1924-$ 1954: Materialien zu einer Verfassungslehre, 3 ed., Berlin, Duncker \& Humblot, 1985, pp. 319326; Clinton Rossiter, Constitutional Dictatorship: Crisis Government in the Modern Democracies, New Brunswick/London, Transaction Publishers, 2002, pp. 31-73; Ernst Rudolf Huber, "Zur Lehre vom Verfassungsnotstand in der Staatstheorie der Weimarer Zeit", en: Hans Schneider (edit.), Im Dienst an Recht und Staat: Festschrift für Werner Weber zum 70. Geburstag, Berlin, Duncker \& Humblot, 1974, pp. 44-46; Ludwig Richter, "Die Vorgeschichte des Art. 48 der Weimarer Reichsverfassung", Der Staat, vol. 37, 1998, pp. 13-26 y Ludwig Richter, "Reichspräsident und Ausnahmegewalt: Die Genese des Artikels 48 in den Beratungen der Weimarer Nationalversammlung”, Der Staat, vol. 37, 1998, pp. 221-247. 
presidenciales. El artículo 48 era preventivo, mientras que la ley habilitante lidiaba con una situación anormal ya existente. Ambos permitían la edición de medidas con fuerza de ley, aunque la ley habilitante podia restringir más derechos que aquellos enumerados en el artículo 48 de la Constitución alemana ${ }^{2}$.

El debate de la doctrina publicista está marcado por las posiciones de Gerhard Anschütz y de Richard Grau en contraposición a Carl Schmitt. Para los dos primeros, la dictadura del presidente tenía como objetivo garantizar la inviolabilidad de la constitución ${ }^{3}$. Por su parte, Carl Schmitt entendía la dictadura del presidente como la autorización para un rompimiento del orden constitucional ${ }^{4}$. Johannes Heckel, en 1932, indagó si la importancia de la dictadura presidencial para el sistema constitucional de Weimar se debía a una mutación constitucional o a una crisis constitucional crónica ${ }^{5}$.

Para Otto Kirchheimer, el artículo 48 de la constitución era una forma de que la clase dominante tomase decisiones, por medio de una dictadura temporal, en una democracia socialmente heterogénea, excluyendo el cuerpo representativo democrático al encontrar la oposición de grandes sectores de la población. La decisión entre la democracia política, la dictadura provisional del artículo 48 o la dictadura permanente con la suspensión de la constitución, sería solamente una cuestión de oportunidad. Sin embargo, Kirchheimer destacó que la decisión sería tomada desde un punto de vista que sería ventajoso para el mantenimiento del statu quo económico 6 .

En 1923, el Gabinete Stresemann utilizó la ley habilitante del 13 de octubre de ese mismo año para solucionar la crisis de la hiperinflación. Aprobada siguiendo los procedimientos de reforma constitucional, previstos en el artículo 76 de la constitución de Weimar, la ley habilitante suspendia provisionalmente algunos artículos constitucionales. Su duración estaba prevista hasta el 31 de marzo de 1924, siempre y cuando no hubiese cambios en la composición del gobierno. Aunque hubo un cambio en el gabinete el 22 de octubre de 1923, la ley dejó de generar efectos el 2 de noviembre de 1923, con la salida de los socialdemócratas del gobierno y la caída del gabinete. El nuevo gabinete,

2 Herbert Tingstén, Les Pleins Pouvoirs: L'Expansion des Pouvoirs Gouvernementaux Pendant et Après la Grande Guerre, Paris, Librairie Stock (Publications du Fonds Descartes), 1934, pp. 301305.

3 Gerhard Anschütz, Die Verfassung des Deutschen Reichs vom 11. August de 1919, reimpr. 14 ed., Aalen, Scientia Verlag, 1987, pp. 269-271 y 275-280; Richard Grau, "Die Diktaturgewalt des Reichspräsidenten", en: Gerhard Anschütz \& Richard Thoma, (coords.), Handbuch des Deutschen Staatsrechts, Tübingen, Mohr Siebeck, 1998, vol. 2, pp. 274-276 y 281-282 y Peter Blomeyer, Der Notstand in den letzten Jahren von Weimar, Berlin, Duncker \& Humblot, 1999, pp. 88-100 y $112-$ 120. Sobre la posibilidad de que los poderes dictatoriales suspendan derechos fundamentales específicos, consulte también Gerhard Anschütz, Die Verfassung des Deutschen Reichs vom 11. August de 1919, op. cit., pp. 288-290; Richard Gau, "Die Diktaturgewalt des Reichspräsidenten", op. cit., pp. 282-284; Johannes Heckel, "Diktatur, Notverordnungsrecht, Verfassungsnotstand", Archiv des öffentlichen Rechts, vol. 22, 1932, pp. 299-303 y Peter Blomeyer, Der Notstand in den letzten Jahren von Weimar, op. cit., pp. 240-245.

4 Peter Blomeyer, Der Notstand in den letzten Jahren von Weimar, op. cit., pp. 100-112.

5 Johannes Heckel, "Diktatur, Notverordnungsrecht, Verfassungsnotstand”, op. cit., pp. 257261.

6 Otto Kirchheimer, "Weimar - und was dann? Analyse einer Verfassung", en: Otto Kirchheimer, Politik und Verfassung, Frankfurt am Main, Suhrkamp, 1964, pp. 18-21. 
presidido por Wilhelm Marx, aprobaria una nueva ley habilitante el 8 de diciembre de 1923, con duración hasta el 15 de febrero de 1924 y la prohibición expresa de restringir cualquier derecho fundamental ${ }^{7}$.

En 1930, Richard Thoma describió la democracia de la Constitución de Weimar como, al mismo tiempo, una gran democracia ("grosse Demokratie"), una democracia pobre ("arme Demokratie') gracias a las condiciones sociales de la población alemana, una democracia oprimida ("bedrückte Demokratie") debido a la pobreza y el desempleo, y una democracia amenazada ("bedrohte Demokratie'), con una rebelión fascista que se estaba organizando en secreto ${ }^{8}$. Con las crisis económicas permanentes de principios de la década de 1930, fue ampliada la utilización del artículo 48 para intentar solucionar las emergencias económicas. Schmitt defendia su utilización, afirmando que era la interpretación adecuada del artículo 48 frente a las necesidades concretas de un Estado económicamente oprimido. Las nociones de seguridad y orden público se trasladaron, de este modo, a la esfera económica9 .

\section{UNIDAD POLÍTICA Y ESTADO PLURALISTA}

Carl Schmitt creía que la incapacidad política del liberalismo habría avanzado al Estado, relativizando y facilitando la pérdida del monopolio de lo político. La crisis del Estado era, en principio, la crisis del Estado burgués de Derecho, que no conseguía integrar las masas en la unidad política10. Esto sucedia porque en el siglo XIX, con la distinción entre Estado y sociedad, el Estado era fuerte para oponerse a las demás fuerzas sociales y convertirse en la referencia de estas fuerzas. Este Estado, separado de la sociedad, era un Estado neutral y no intervencionista, y por consiguiente no buscaba suprimir lo no político. Esta situación cambió radicalmente cuando la antítesis de la estructura dualista de Estado y sociedad desapareció y el Estado se convirtió en

7 Herbert Tingstén, Les Pleins Pouvoirs, op. cit., pp. 290-321; Achim Kurz, Demokratische Diktatur? Auslegung und Handhabung des Artikels 48 der Weimarer Verfassung 1919-25, Berlin, Duncker \& Humblot, 1992, pp. 152-162 y Gerald D. Feldman, The Great Disorder: Politics, Economics, and Society in the German Inflation, 1914-1924, Oxford/New York, Oxford University Press, 1997, pp. 740-757 y 807-810.

8 Richard Thoma, "Das Reich als Demokratie", en: Gerhard Anschütz \& Richard Thoma, (coords.), Handbuch des Deutschen Staatsrechts, op. cit., vol. 1, pp. 187-188.

9 Carl Schmitt, Der Hüter der Verfassung, 4 ed., Berlin, Duncker \& Humblot, 1996, pp. 115121; Johannes Heckel, "Diktatur, Notverordnungsrecht, Verfassungsnotstand”, op. cit., pp. 319338; Frederick Mundell Watkins, The Failure of Constitutional Emergency Powers under the German Republic, Cambridge (Ms.), Harvard University Press, 1939, pp. 20 y 73-85; Clinton Rossiter, Constitutional Dictatorship, op. cit., pp. 41-43 y 51-53; Ernst Rudolf Huber, "Zur Lehre vom Verfassungsnotstand in der Staatstheorie der Weimarer Zeit”, op. cit., pp. 37-41; Achim Kurz, Demokratische Diktatur?, op. cit., pp. 152-168; Peter Blomeyer, Der Notstand in den letzten Jahren von Weimar, op. cit., pp. 81-88, 181-188, 227-240 y 382-415 y William E. Scheuerman, "The Economic State of Emergency", Cardozo Law Review, vol. 21, 2000, pp. 1882-1890. Como destacó Tingstén, a principios de la década de 1930, la dictadura gubernamental de los gobiernos Brüning y von Papen fue fundada en el uso sistemático de los poderes excepcionales del artículo 48, no en alguna ley habilitante. Cf. Herbert Tingstén, Les Pleins Pouvoirs, op. cit., nota 81, p. 326.

10 Carl Schmitt, "Der bürgerliche Rechtsstaat", en: Carl Schmitt, Staat, Grossraum, Nomos: Arbeiten aus den Jahren 1916-1969, Berlin, Duncker \& Humblot, 1995, pp. 48-50 y Carlo Galli, Genealogia della Politica: Carl Schmitt e la Crisi del Pensiero Politico Moderno, Bologna Il Mulino, 1996, pp. 519-521. 
autoorganización de la sociedad. Todos los problemas sociales y económicos se convirtieron, de ese modo, en problemas políticos. Este Estado resultante de la autoorganización de la sociedad no podía ser realmente separado de ella y englobaba todo lo que tenía relación con la convivencia humana. El Estado interfería en todos los sectores de la vida social, sin que existiera nada que no fuera estatal y político ${ }^{11}$. Este Estado era el Estado Total ${ }^{12}$, que analizaremos más detenidamente más adelante.

En este contexto de Estado Total, el Parlamento, por haber supuesto la división entre Estado y sociedad, se convirtió en una estructura que encerraba en sí misma una contradicción que negaba las premisas de su victoria. Esencialmente, la distinción entre Estado y sociedad desapareció justamente con la democratización y el triunfo del Parlamento, con el Estado convirtiéndose en la autoorganización de la sociedad ${ }^{13}$. Para Schmitt, de este modo, no podría pasar desapercibida la diferencia entre las tradicionales ideas parlamentarias liberales y las ideas de la democracia de masas moderna ${ }^{14}$. La situación del parlamentarismo era grave porque la evolución de la democracia de masas convirtió la discusión pública en formalidad vacía. Para los partidos políticos, la cuestión ya no era convencer a sus adversarios, sino conseguir la mayoría para gobernar $^{15}$. El parlamentarismo liberal, así, negaría las experiencias políticas auténticas, pues presuponia que los conflictos y tensiones politicas podian ser solucionados por medio del debate y de la negociación. Para Schmitt, el parlamentarismo liberal era anti-politico, y por consiguiente la fe en el parlamentarismo era propia del liberalismo, no de la democracia. Una característica de la democracia era la homogeneidad ${ }^{16}$.

El fundamento de la democracia en la identidad y en la homogeneidad del pueblo consistía en el aspecto existencial de la unidad política. Para Schmitt, el principio político auténticamente democrático no era el de la libertad, sino el de la identidad o igualdad sustancial. Sin embargo, la igualdad democrática estaría ligada a la desigualdad, pues, para Schmitt, la igualdad era politica, y por consiguiente discriminatoria, debiendo tratar igualmente los iguales y definir al enemigo. La igualdad politica de la democracia debe corresponder al principio de la homogeneidad, a partir del cual y en nombre del cual pueda ser establecida la

11 Carl Schmitt, Der Hüter der Verfassung, op. cit., pp. 73-75 y 77-79. Consulte también Paul Hirst, "Carl Schmitt's Decisionism“, Telos, 72, 1987, pp. 17-18; Jean François Kervégan, Hegel, Carl Schmitt: Le Politique entre Spéculation et Positivité, Paris, PUF, 1992, p. 65 y Olivier Beaud, Les Derniers Jours de Weimar: Carl Schmitt face à l'Avènement du Nazisme, Paris, Descartes \& Cie., pp. 61-63.

12 La expresión "Estado Total" aparece por primera vez en el libro O Guardião da Constituição por Der Hüter der Verfassung [El Guardián de la Constitución], que es una reunión de varios artículos.

13 Carl Schmitt, Der Hüter der Verfassung, op. cit., pp. 82-83.

14 Carl Schmitt, Die geistesgeschichtliche Lage des heutigen Parlamentarismus, 8 ed., Berlin, Duncker \& Humblot, Berlin, 1996, p. 6.

15 Carl Schmitt, Die geistesgeschichtliche Lage des heutigen Parlamentarismus, op. cit., pp. 1013. Sobre la discusión pública y la publicidad como principios del parlamentarismo y su desaparición, consulte Carl Schmitt, Die geistesgeschichtliche Lage des heutigen Parlamentarismus, op. cit., pp. 43-50 y 61-63.

16 Carl Schmitt, Die geistesgeschichtliche Lage des heutigen Parlamentarismus, op. cit., pp. 1320 y William E. Scheuerman, Carl Schmitt: The End of Law, Lanham/New York/Oxford, Rowman \& Littlefield Publishers, 1999, pp. 44-45. 
distinción entre ciudadano y extranjero, entre iguales y desiguales, entre amigo y enemigo. De acuerdo con Kervégan, esta idea de homogeneidad sustancial no conduciría necesariamente a la discriminación racial, del mismo modo que la distinción amigo/enemigo no implicaría en exterminio. Sin embargo, lo que para él debe ser destacado es que ésta es la interpretación del propio Schmitt con base en su opción política de 1933. Fue solamente Carl Schmitt quien, de 1933 en adelante, entendió homogeneidad e identidad como pureza racial ${ }^{17}$.

Las dificultades de funcionamiento del parlamentarismo habrian surgido a partir de nuevas situaciones creadas por la democracia de masas, con su pretensión de realizar la identidad entre gobernantes y gobernados, que se enfrentó al envejecido Parlamento liberal. En la opinión de Schmitt, cuanto mayor fuese el sentimiento democrático, más se vería patente que la democracia no debería estar limitada a las elecciones ${ }^{18}$. Habría, así, una contradicción entre el individualismo liberal y la homogeneidad del Estado democrático ${ }^{19}$. La democracia estaria formada por fuerzas esencialmente politicas, al contrario del liberalismo, que llevarian al Estado Total ${ }^{20}$.

Con la expansión del sufragio y la democracia, el deseo de ampliar las identidades había aumentado, contra los formalismos estériles del Parlamento liberal. El parlamentarismo del siglo XIX, para Schmitt, estaba dominado por las clases privilegiadas, con énfasis en los presupuestos burgueses de la instrucción y de la propiedad privada. Con el ascenso de las masas industriales de trabajadores y la consolidación de la democracia, estos presupuestos liberales no tendrían más sentido. Además, la emergencia de los partidos de masa convirtió el Parlamento en el local de la disputa entre bloques de poder antagónicos que

17 Carl Schmitt, Verfassungslehre, 8 ed., Berlin, Duncker \& Humblot, 1993, pp. 223, $226-228$ y 234-238; Hasso Hofmann, Legitimität gegen Legalität: Der Weg der politischen Philosophie Carl Schmitts, 4 ed., Berlin, Duncker \& Humblot, 2002, pp. 123-134; Carlo Galli, Genealogia della Politica, op. cit., pp. 537-539 y 588-589; Olivier Beaud, Les Derniers Jours de Weimar, op. cit., pp. 85-86; David Dyzenhaus, Legality and Legitimacy: Carl Schmitt, Hans Kelsen and Hermann Heller in Weimar, Oxford/New York, Oxford University Press, 1999, pp. 56-57 y William E. Scheuerman, Carl Schmitt, op. cit., pp. 43-44.

18 En este sentido, Schmitt afirma que el fascismo es lo opuesto al liberalismo, no a la democracia. La renuncia a las elecciones no es antidemocrática, sino que antiliberal. La votación uninominal secreta es un principio liberal, no democrático, porque degrada la formación de la voluntad estatal, eliminando el pueblo como unidad del ámbito político. Cf. Carl Schmitt, "Wesen und Werden des faschistischen Staates", en: Carl Schmitt, Positionen und Begriffe im Kampf mit Weimar-Genf-Versailles, 1923-1939, 3 ed., Berlin, Duncker \& Humblot, 1994, pp. 125-127.

19 Carl Schmitt, Die geistesgeschichtliche Lage des heutigen Parlamentarismus, op. cit., pp. 2123. Consulte también Hasso Hofmann, Legitimität gegen Legalität, op. cit., pp. 88-94 y Heinrich Meier, Die Lehre Carl Schmitts: Vier Kapitel zur Unterscheidung Politischer Theologie und Politischer Philosophie, Stuttgart/Weimar, Metzler, 1994, pp. 217-219. En visión contraria, Renato Cristi defiende la hipótesis de que Schmitt habria separado al liberalismo de la democracia para intentar preservar el parlamentarismo. En su opinión, el objetivo de Schmitt era la democracia, no el liberalismo, buscando reformar el parlamentarismo, excluyendo sus elementos democráticos, para salvar la unidad política. Cf. Renato Cristi, "Le Restaurant Cosmopolite - Libéralisme, Démocratie et Catholicisme chez Carl Schmitt”, en: Renato Cristi, Le Libéralisme Conservateur: Trois Essais sur Schmitt, Hayek et Hegel, Paris, Éditions Kimé, 1993, pp. 23-26, 28 y $40-45$ y Renato Cristi, Carl Schmitt and Authoritarian Liberalism: Strong State, Free Economy, Cardiff, University of Wales Press, 1998, pp. 17-18, 21-22 y 79-90.

20 Carl Schmitt, Der Begriff des Politischen: Text von 1932 mit einem Vorwort und drei Corollarien, 6 ed., Berlin, Duncker \& Humblot, 1996, pp. 68-69. 
deseaban conquistar el poder del Estado, es decir, el local de los intereses pluralistas controlados por bloques polarizados. De este modo, el Parlamento dejó de ser un local de decisión política. La democratización del Legislativo había generado una divergencia entre sus decisiones y los intereses capitalistas de la burguesía alemana, lo que favoreció de ese modo el poder presidencial de legislar por medidas (Maßnahme) para solucionar, a su favor, los problemas de dirección económica y de distribución, disputada durante la República por las más variadas fuerzas económicas y políticas $^{21}$.

De ese modo, los partidos de masa ocuparon el Estado, y su pluralismo era, para Schmitt, nocivo a la unidad política. El Parlamento, lejos de ser la solución, volvió evidente el problema de la unidad política alemana. En el pluralismo, cada estructura organizada de poder (incluso los partidos politicos) buscaba realizar en sí misma y para sí misma la totalidad. Alemania tendría, así, "partidos totales" ("totalen parteien'), que buscaban la politización total, con la pérdida del monopolio de lo político por el Estado. El Estado era objeto de la explotación de los partidos. Y el Parlamento era instrumentalizado por los partidos en su lucha unos contra otros y en la lucha contra el gobierno y el Estado. El Estado Parlamentario era un Estado de Partidos de coalición inestable (labiler KoalitionsPartien-Staat). De este modo, según Carl Schmitt, en vez de ser el escenario donde actuaban representantes nacionales libres, en lugar de ser el transformador de los intereses de partido en una voluntad por encima de ellos, el Parlamento se convirtió en el teatro de la distribución pluralista de los poderes sociales organizados. Fueron dos las consecuencias inevitables de esta situación: hubo la incapacidad de obtención de mayorias y de actuación debido al pluralismo o la mayoria que eventualmente se buscaba utilizar todas las posibilidades legales como instrumento y medio de asegurar su poder. Cuando el Estado se transformó en una estructura pluralista, no había más fidelidad al Estado o a la Constitución, sino fidelidad a la organización social, poniendo en riesgo la formación de la unidad política ${ }^{22}$.

21 Carl Schmitt, Die geistesgeschichtliche Lage des heutigen Parlamentarismus, op. cit., pp. 3436; Carl Schmitt, "Der bürgerliche Rechtsstaat", op. cit., pp. 46-47; Carl Schmitt, Verfassungslehre, op. cit., pp. 310-313; Ingeborg Maus, Bürgerliche Rechtstheorie und Faschismus: Zur sozialen Funktion und aktuellen Wirkung der Theorie Carl Schmitts, 2 ed., München, Wilhelm Fink Verlag, 1980, pp. 25-27 y William E. Scheuerman, Carl Schmitt, op. cit., pp. 40-43 y 50-51. Para la critica de Schmitt al parlamentarismo y a la Partitocracia (Parteienstaat), consulte también, Lutz-Arwed Bentin, Johannes Popitz und Carl Schmitt: Zur wirtschaftlichen Theorie des totalen Staates in Deutschland, München, C. H. Beck, 1972, pp. 88-91; Carlo Galli, Genealogia della Politica, op. cit., pp. 516-519; Michael Stolleis, Geschichte des öffentlichen Rechts in Deutschland, München, C.H. Beck, 1999, vol. 3, pp. 105-109; John P. McCormick, Carl Schmitt's Critique of Liberalism: Against Politics as Technology, Cambridge, Cambridge University Press, 1999, pp. 170-175 y 179-189 y William E. Scheuerman, Carl Schmitt, op. cit., pp. 51-60.

22 Carl Schmitt, Der Hüter der Verfassung, op. cit., pp. 71-73 y 83-91 y Carl Schmitt, "Weiterentwicklung des totalen Staats in Deutschland", en: Carl Schmitt, Positionen und Begriffe im Kampf mit Weimar-Genf-Versailles, op. cit., pp. 214-216. Consulte también Carlo Galli, Genealogia della Politica, op. cit., pp. 641-643 y 647-650; Carlo Galli, "Strategie della Totalità: Stato Autoritario, Stato Totale, Totalitarismo, nella Germania degli Anni Trenta", Filosofia Politica, ano XI, n. 1, 1997, pp. 33-35 y Renato Cristi, Carl Schmitt and Authoritarian Liberalism, op. cit., pp. 179-182. 


\section{EL PRESIDENTE DEL REICH Y EL ESTADO DE EMERGENCIA ECONÓMICO}

Si los órganos e instancias previstos en la Constitución no eran capaces de realizar la unidad politica, era inevitable, según Schmitt, que la sustancia política se desplazase hacia otros sectores del sistema político y social. La solución no podia, sin embargo, ser la continuidad del debilitamiento del Estado. Para que se pudiese imponer la neutralidad, era necesario un Estado fuerte, pues la solución era política y exigía la capacidad de toma de decisiones. La salida era un poder neutralizador que, utilizándose de los poderes de excepción, conseguiría excluir quien fuese hostil o ajeno al orden politico, pudiendo contraponer la legitimidad a la legalidad y, así, excluir al enemigo. Como en las situaciones críticas, la solución de los problemas se alejó del Parlamento, y el artículo 48 de la Constitución de Weimar ganó, de ese modo, una importancia crucial23.

El poder del Presidente del Reich de promulgar decretos con fuerza de ley, de acuerdo con la segunda parte del artículo 48, se volvía esencial cuando la situación excepcional y de necesidad se desarrolla en el ámbito económico y financiero, cuando se trataba de un "estado de emergencia económica" (Wirtschaftsnotstand o wirtschaftliche Not- und Ausnahmezustand). Schmitt afirmó que era admisible, bajo la presión de ciertos estados de necesidad esencialmente económicos, la posibilidad de aplicar las atribuciones extraordinarias del artículo 48 de la Constitución. Al final, los requisitos de estas atribuciones extraordinarias (estado de excepción, peligro considerable para la seguridad y orden públicos) también podrian estar fundados en una situación de necesidad económica y financiera o en un peligro que resultase de ella. El carácter inicialmente económico y financiero de la situación, así, no excluiría la aplicación de las medidas extraordinarias. En consecuencia, según Schmitt, existiría el derecho de que el Presidente del Reich promulgase, con fuerza de ley, decretos de materia y carácter económico y financiero. Schmitt justificó esta interpretación del artículo 48 de la Constitución alegando que era la interpretación adecuada a las peculiaridades concretas de la situación excepcional de un Estado económicamente oprimido y que, al mismo tiempo, soportaba grandes cargas sociales $^{24}$.

23 Carl Schmitt, Der Hüter der Verfassung, op. cit., pp. 100-101 y 115-117. Consulte también Carl Schmitt, "Reichspräsident und Weimarer Verfassung", en: Carl Schmitt, Staat, Grossraum, Nomos, op. cit., pp. 24-32 y Carlo Galli, Genealogia della Politica, op. cit., pp. 644-647. Consulte también Frederick Mundell Watkins, The Failure of Constitutional Emergency Powers under the German Republic, op. cit., pp. 16-24; Clinton Rossiter, Constitutional Dictatorship, op. cit., pp. 6173; Christoph Gusy, Die Weimarer Reichsverfassung, Tübingen, Mohr Siebeck, 1997, pp. 107-113 y Michael Stolleis, Geschichte des öffentlichen Rechts in Deutschland, op. cit., vol. 3, pp. $114-116$.

24 Carl Schmitt, Der Hüter der Verfassung, op. cit., pp. 117-121. Consulte también Carl Schmitt, "Legalität und Legitimität", op. cit., pp. 319-323; Frederick Mundell Watkins, The Failure of Constitutional Emergency Powers under the German Republic, op. cit., pp. 73-85; Clinton Rossiter, Constitutional Dictatorship, op. cit., pp. 41-49 y 51-53; Ingeborg Maus, “Zur 'Zäsur' von 1933 in der Theorie Carl Schmitts", en: Ingeborg Maus, Rechtstheorie und Politische Theorie im Industriekapitalismus, München, Wilhelm Fink Verlag, 1986, pp. 96-97; Carlo Galli, Genealogia della Politica, op. cit., pp. 660-661 y William E. Scheuerman, "The Economic State of Emergency", op. cit., pp. 1882-1891. Para la reconstrucción del debate jurídico de la República de Weimar sobre el Wirtschaftsnotstand, consulte también Peter Blomeyer, Der Notstand in den letzten Jahren von Weimar, op. cit., pp. 85-120. 
De acuerdo con Schmitt, en la historia constitucional europea siempre hubo el privilegio de la ley formal en materia económica y financiera debido a la ficción de un Estado que no se involucraba con la economía. La Constitución de Weimar, por su parte, no siguió esa tradición, pues el artículo 48 incluyó, entre los derechos fundamentales susceptibles de suspensión por el Presidente del Reich, la propiedad privada (artículo 153), haciendo posibles, así, las restricciones de la libertad contractual y económica por medio de medidas (Maßnahmen) provenientes del Poder Ejecutivo25.

Schmitt insistía, por otra parte, en que el Parlamento debería respetar la generalidad de la ley ${ }^{26}$. La racionalidad formal de la ley, beneficiaria de los intereses burgueses en el capitalismo liberal, ya había sido modificada en el período weimariano. La concentración del poder económico redujo la importancia de las leyes generales, que presumian una situación de agentes económicos en relativa igualdad de condiciones. Las medidas que hacian regulaciones individuales posibles frente a los monopolios individuales se volvieron más comunes. Las diferencias de una sociedad pluralista también eliminaron buena parte del sentido de la generalidad abstracta de la ley. Con la intervención creciente del Estado en la economía y la consecuente organización de las demandas sociales junto al Estado, la heterogeneidad de los intereses socioeconómicos pasó a reflejarse en la especialidad de los contenidos legislativos. Además, la ley pasó a beneficiar, también, grupos antes desprivilegiados, pero que ahora tenían representación en el Parlamento ${ }^{27}$.

En contraposición a esto, Schmitt reiteró no sólo la necesidad de las medidas individuales en materia económica y financiera, sino también que el

25 Carl Schmitt, Der Hüter der Verfassung, op. cit., pp. 127-128. Consulte también Carl Schmitt, "Legalität und Legitimität", op. cit., pp. 323-326. Franz Neumann, por otro lado, destaca que el Presidente del Reich no podria suspender los derechos sociales, excluidos de la lista prevista en el artículo 48 de la Constitución. Consulte Franz Neumann, "Libertà di Coalizione e Costituzione: La Posizione dei Sindacati nel Sistema Costituzionale", en: Franz Neumann, $\Pi$ Diritto del Lavoro fra Democrazia e Dittatura, Il Mulino, Bologna, 1983, pp. 159-160. Sobre la suspensión de derechos fundamentales con base en el artículo 48 de la Constitución de Weimar, consulte Achim Kurz, Demokratische Diktatur?, op. cit., pp. 71-76.

26 Schmitt intenta, de acuerdo con Ingeborg Maus, limitar el Parlamento al concepto liberalconstitucional de ley, en contraposición a los autores positivistas, cuyo concepto de ley formal favorecía el crecimiento de la autoridad del Poder Legislativo, que ya no era controlado exclusivamente por la burguesía. Cf. Ingeborg Maus, "Zur 'Zäsur' von 1933 in der Theorie Carl Schmitts”, op. cit., p. 96. Consulte también Germán Gómez Orfanel, Excepción y Normalidad en el Pensamiento de Carl Schmitt, Madrid, Centro de Estudios Constitucionales, 1986, pp. $173-179$. Sobre la insuficiencia del concepto formal de ley, consulte Carl Schmitt, Verfassungslehre, op. cit., pp. 143-146. Para contraponerse a ese concepto formal, Schmitt propone un concepto politico de ley, que es un concepto material: la ley en sentido politico consiste en la voluntad y el mandato concretos, o sea, es un acto de soberanía, lo que incluiría las medidas con fuerza de ley del Presidente del Reich. Consulte Carl Schmitt, Verfassungslehre, op. cit., pp. 146-150 y Germán Gómez Orfanel, Excepción y Normalidad en el Pensamiento de Carl Schmitt, op. cit., pp. 167-173. Sobre la polémica jurídica relacionada a las medidas, consulte también Carl Schmitt, "Die Diktatur des Reichspräsidenten nach Artikel 48 der Weimarer Verfassung", en: Carl Schmitt, Die Diktatur: Von den Anfängen des modernen Souveränitätsgedankens bis zum proletarischen Klassenkampf, 6 ed., Berlin, Duncker \& Humblot, 1994, pp. 240-253 y Carl Schmitt, "Legalität und Legitimität", op. cit., pp. 331-335. Para el concepto de medida (Maßnahme) de Schmitt, consulte Achim Kurz, Demokratische Diktatur?, op. cit., pp. 168-174 y Germán Gómez Orfanel, Excepción y Normalidad en el Pensamiento de Carl Schmitt, op. cit., pp. 219-224.

27 Ingeborg Maus, “Zur 'Zäsur' von 1933 in der Theorie Carl Schmitts”, op. cit., pp. 97-98. 
Parlamento debía limitarse a la elaboración de leyes generales, en conformidad con el artículo 109 de la Constitución de Weimar. De acuerdo con Ingeborg Maus, acompañando la clásica interpretación de Franz Neumann, lo que Schmitt buscaba era racionalizar el contenido de las leyes, limitando el poder del Parlamento, que ya no garantizaba los derechos y privilegios burgueses. La garantía de esos derechos y privilegios estaria en manos del Presidente del Reich, que monopolizaba la autoridad en la cuestión de las medidas individuales. Paradójicamente, en un Estado Social como el de Weimar, las medidas legislativas del Ejecutivo no democráticamente controlado serian vistas por los sectores privilegiados como una garantía contra la actuación del Parlamento, que ya no estaba limitado a representar sus intereses. La autonomía de estos grupos sociales identificados con el Estado estaba amenazada, en Weimar, por los sectores antes desprivilegiados. Sólo un Estado fuerte podría volver a garantizar su autonomía y sus intereses. Para Maus, Schmitt habria luchado en nombre de las demandas liberal-burguesas contra la institución liberal-burguesa del Parlamento 28 .

Las objeciones a los decretos económicos con fuerza de ley, para Schmitt, se debían a concepciones superadas. Si el Parlamento era incapaz de actuar, no podría exigir que los demás órganos constitucionales también fuesen incapaces de actuar. El desarrollo de la práctica del estado de excepción en el aspecto económico, con la promulgación de decretos con fuerza de ley, no surgió casualmente o por alguna arbitrariedad, sino que, de acuerdo con Schmitt, correspondería a las necesidades históricas, estando alineado con la ordenación entonces existente. Schmitt afirmaba que el estado de emergencia económico era una forma de salvar al Estado Legislativo, cuyo órgano representativo estaba dividido de modo pluralista, buscando liberarlo del pluralismo anticonstitucional. Constitucionalmente, esto sólo podría ser realizado por el Presidente del Reich ${ }^{29}$.

El Presidente del Reich era, para Schmitt, un poder neutral (pouvoir neutre et intermédiaire) en el mismo nivel de los demás poderes, pero revestido de atribuciones especiales con posibilidades de intervención específicas (artículo 48 de la Constitución). En un Estado como el alemán, federal, policrático y pluralista, la función mediadora y reguladora del poder neutro adquirió importancia central en el sistema político. El Presidente del Reich era, de ese

28 Franz Neumann, "The Change in the Function of Law in Modern Society", en: Franz Neumann, The Democratic and the Authoritarian State: Essays in Political and Legal Theory, The Free Press, Glencoe, 1957, pp. 50-53 y Ingeborg Maus, “Zur 'Zäsur' von 1933 in der Theorie Carl Schmitts", op. cit., pp. 98-100. Consulte también la crítica de Hermann Heller, "Der Begriff des Gesetzes in der Reichsverfassung” en: Hermann Heller, Gesammelte Schriften, 2 ed., Tubingen, J. C. B. Mohr (Paul Siebeck), 1992, vol. 2, pp. 214-217; Otto Kirchheimer, "Weimar - und was dann? Analyse einer Verfassung", op. cit., pp. 18-21 y Renato Cristu, Carl Schmitt and Authoritarian Liberalism, op. cit., p. 193. Para una interpretación similar sobre la critica fascista a los parlamentos y a la democracia, consulta Karl Polanyi, The Great Transformation: The Political and Economic Origins of Our Time, 2 ed., Boston, Beacon Press, 2001, pp. 196-197, 199-200, 234 y 243-244.

29 Carl Schmitt, Der Hüter der Verfassung, op. cit., pp. 128-131. Aún con relación al debate jurídico de la época al respecto de la concepción y el alcance de las medidas (Maßnahmen), consulte Achim Kurz, Demokratische Diktatur?, op. cit., pp. 59-77 y 167-186. 
modo, el último pilar del orden constitucional, el único capaz de resistir la posibilidad de $\operatorname{caos}^{30}$.

La posibilidad de generación de voluntad política, con la superación de los métodos desintegradores del Estado pluralista de partidos, estaba, para Schmitt, garantizada por la independencia del sistema plebiscitario (Presidente) frente al sistema parlamentario. Esta independencia del Presidente, sin embargo, era con relación a los partidos políticos, no a la política. El Presidente del Reich era el centro de un sistema de fundamentos plebiscitarios de neutralidad e independencia con relación a los partidos políticos. Al Presidente estaba condicionada la ordenación política de Alemania, en la medida en que el pluralismo llegaba a hacer imposible el funcionamiento del Parlamento. De este modo, el Guardián de la Constitución (Hüter der Verfassung) era, de acuerdo con Carl Schmitt, el Presidente del Reich que, en caso de necesidad, tenía atribuciones eficaces que le permitian realizar una defensa activa del orden constitucional. El hecho de que el Presidente fuera el guardián correspondia, también, al principio democrático de la Constitución, porque él era elegido por todo el pueblo, y sus facultades politicas frente al Poder Legislativo (poder de disolver la Cámara de los Diputados - Reichstag - y poder de convocar plebiscitos) eran un contrapeso para el pluralismo de los grupos sociales y económicos del poder, además de garantizar la unidad del pueblo alemán como conjunto político. El presidente del Reich, de acuerdo con Schmitt, tenía autoridad para vincularse directamente a la voluntad política del conjunto del pueblo alemán y podía actuar como guardián de la unidad constitucional y de la integridad de la nación ${ }^{31}$.

\section{EL ESTADO TOTAL}

En la visión de Carl Schmitt, la evolución del Estado moderno pasa necesariamente por las etapas de Estado Absoluto, Estado Neutral y Estado Total, que significan, respectivamente, la unificación religiosa, la unificación nacional y la cohesión económica ${ }^{32}$. El Estado Total reemplazó al Estado Neutro

30 Carl Schmitt, Verfassungslehre, op. cit., pp. 350-353; Carl Schmitt, Der Hüter der Verfassung, op. cit., pp. 71-73 y 132-140; Carl Schmitt, "Legalität und Legitimität”, op. cit., pp. 338-341 y Carl Schmitt, "Weiterentwicklung des totalen Staats in Deutschland", op. cit., p. 216. Consulte también Vilmos Holczhauser, Konsens und Konflit: Die Begriffe des Politischen bei Carl Schmitt, Berlin, Duncker \& Humblot, 1990, pp. 155-161; Peter Blomeyer, Der Notstand in den letzten Jahren von Weimar, op. cit., pp. 199-216 y 404-415 y David Dyzenhaus, Legality and Legitimacy, op. cit., pp. 72-83. Sobre la influencia de las concepciones de Max Weber con relación al papel del Presidente del Reich en la Constitución de Weimar en la teoría de Carl Schmitt, consulte Wolfgang Mommsen, Max Weber et la Politique Allemande, 1890-1920, Paris, PUF, 1985, pp. 477-486. Mommsen, sin embargo, reconoce que Schmitt va más allá de lo propuesto por Weber, porque su jefe plebiscitario tiene una orientación contraria al princípio representativo y su autoridad se contrapone al pluralismo de los partidos políticos.

31 Carl Schmitt, Der Hüter der Verfassung, op. cit., pp. 156-159. La crítica de Johannes Popitz, amigo cercano de Schmitt que era un importante especialista en finanzas, burocrata renombrado y vinculado a los medios políticos conservadores de Prusia, al régimen parlamentario y su defensa de los poderes de excepción del Presidente es similar y ejerció gran influencia en las propuestas de Carl Schmitt. Consulte Hildemarie Dieckmann, Johannes Popitz: Entwicklung und Wirksamkeit in der Zeit der Weimarer Republik, Berlin/Dahlen, Colloquium Verlag, 1960, pp. 135-140.

32 Cf. Pier Paolo Portinaro, La Crisi dello Jus Publicum Europaeum: Saggio su Carl Schmitt, Milano, Edizioni di Comunità, 1982, pp. 140-141. Sobre el origen del concepto schmittiano de Estado Total, consulte Lutz-Arwed Bentin, Johannes Popitz und Carl Schmitt, op. cit., pp. 105-107. 
del siglo XIX, trayendo una serie de nuevos desafios con la transformación de todos los problemas económicos y sociales en cuestiones potencialmente politicas. Para Schmitt, el Estado Total promovía la politización (Politisierung) de todo lo que fuera económico, social, cultural y religioso ${ }^{33}$.

El Estado Liberal neutral y no intervencionista tenía autonomía frente a la sociedad. Con la separación clara entre Estado y sociedad, el Estado Neutral tenía capacidad genuinamente política. De esta forma, la ecuación Estado = politico estaba correcta, pues el Estado constituía un hecho claro y determinado en contraposición a los grupos y esferas no políticos, o sea, el Estado mantenía el monopolio de lo político, encontrándose separado y por encima de la sociedad. La extensión y amplitud del sufragio y de la democracia, sin embargo, eliminaron la separación Estado/sociedad. El Estado ya no estaba por sobre las fuerzas sociales, porque el pueblo había ocupado el Estado, que pasó a ser la autoorganización de la sociedad. En consecuencia, el Estado debería satisfacer todas las necesidades y demandas de la población, interviniendo en los ámbitos económico y social, abandonando así las posturas de neutralidad y no intervención estatal. A medida que el Estado y la sociedad se fundieron, generando la identidad entre Estado y sociedad (el Estado Total), todos los dominios pasaron a ser politicos, o sea, ya no había como distinguir lo político, y aquella identificación entre Estado y político, para Schmitt, había dejado de ser verdadera ${ }^{34}$.

Para entender el Estado Total, debemos utilizar también otra clasificación de los Estados elaborada por Schmitt. Todos los Estados, para él, podían, además, ser clasificados de acuerdo con la zona de actividad política en que el centro de su actividad se encontraba. Este centro de actividad, en cada momento histórico, sólo se manifestaba claramente en la situación de excepción. De este modo, para Schmitt, existian Estados jurisdiccionales (Jurisdiktionsstaat), gobernadores (Regierungsstaat), legislativos (Gesetzgebungsstaat) y administrativos (Verwaltungsstaat). Obviamente, no existian tipos puros, además del hecho de que la clasificación de Schmitt no era una elaboración teórica específica, sino un fruto secundario de su análisis y crítica del Estado Legislativo Parlamentario ${ }^{35}$.

El Estado Legislativo se caracterizaba por tener la expresión suprema y decisiva de la voluntad común en la ley, reduciendo la legitimidad (del monarca o del pueblo) a la legalidad ${ }^{36}$. Este Estado Legislativo era la forma típica del Estado Neutral o Estado Liberal del siglo XIX y que, según Schmitt, estaría también previsto en la Constitución de Weimar. El Estado Total, por su naturaleza, era un Estado Administrativo. En este tipo de Estado existe el reemplazo progresivo de las leyes por medidas, motivadas por criterios "técnicos" para satisfacer las exigencias de las condiciones reales y efectivas, como forma dominante del

33 Carl Schmitt, "Weiterentwicklung des totalen Staats in Deutschland”, op. cit., p. 211.

34 Carl Schmitt, Der Begriff des Politischen, op. cit., pp. 20-26; Vilmos Holczhauser, Konsens und Konflit, op. cit., pp. 167-168 y William E. Scheuerman, Carl Schmitt, op. cit., pp. 87-90.

35 Carl Schmitt, Der Hüter der Verfassung, op. cit., pp. 75-77 y Carl Schmitt, "Legalität und Legitimität”, op. cit., pp. 263-274, especialmente pp. 264-269. Consulte también Mario Nigro, "Carl Schmitt e lo Stato Amministrativo", Rivista Trimestrale di Diritto e Procedura Civile, Anno XL, 3, septiembre, 1986, p. 772 .

36 Carl Schmitt, "Legalität und Legitimität”, op. cit., pp. 263-264, 269-271 y 274-283 y Mario Nigro, "Carl Schmitt e lo Stato Amministrativo", op. cit., pp. 774-777. 
ejercicio de la actividad estatal, considerando la imposibilidad de concretar todas las tareas estatales por vía legislativa. Con el Estado Administrativo, percibimos una atenuación de la distinción clara entre elaboración y aplicación de la ley, típica del Estado Legislativo. La Administración es el centro de su actividad, el punto esencial de la voluntad politica decisiva ${ }^{37}$.

El Estado Administrativo utilizaba un fuerte argumento de los enemigos de la República de Weimar: el de la neutralidad y despolitización de la burocracia contra el Estado de Partidos. Schmitt destacó la creciente legitimidad autónoma del poder administrativo como consecuencia de la crisis de legalidad del Estado Legislativo Parlamentario. La crisis de la legalidad formal, asi, tendría la función de traer a la superficie el núcleo más auténtico del poder estatal, la burocracia. El ejército y la burocracia permitirian una nueva base para la legitimidad plebiscitaria del Presidente. El Estado Administrativo, de este modo, sería formado, de acuerdo con Fioravanti, por un complejo constitucional plebiscito/Presidente/burocracia. Este Estado se organizó contra la reducción de la burocracia a instrumento de la voluntad de la mayoría parlamentaria, considerando que el Parlamento estaba a un paso de capitular frente al pluralismo de los intereses organizados, garantizando la especificidad de lo politico ${ }^{38}$.

El Estado Total era, además de un Estado Administrativo, un Estado Económico (Wirtschaftsstaat). Al fin y al cabo, con el fin de la distinción entre Estado y sociedad, todos los problemas sociales y económicos pasaron a ser estatales. Sin embargo, los centros de decisión económica se autonomizaban con relación al Estado, caracterizando lo que Johannes Popitz denomina de "policracia" 39. La policracia, para Schmitt, es el conjunto de titulares, jurídicamente autónomos, de la economía pública, en cuya independencia la voluntad política encuentra una limitación. La consecuencia de la policracia fue la falta de una línea homogénea, la desorganización y la aversión al plan, fundamental en la transición hacia el Estado Económico. La policracia de la economía pública coincidió con la quiebra pluralista del Estado Legislativo y su evolución hacia el Estado Total. Esta especie de "refeudalización" de la función

37 Carl Schmitt, "Legalität und Legitimität", op. cit., pp. 266-268; Mario Nigro, "Carl Schmitt e lo Stato Amministrativo", op. cit., pp. 780-782 y Jean François Kervégan, Hegel, Carl Schmitt, op. cit., pp. 95-100. Para la crítica al Estado Administrativo de Schmitt, consulte Mario Nigro, "Carl Schmitt e lo Stato Amministrativo", op. cit., pp. 786-789.

38 Bernardo Sordi, Tra Weimar e Vienna: Amministrazione Pubblica e Teoria Giuridica nel Primo Dopoguerra, Milano, Giuffrè, 1987, pp. 344-367 y Maurizio Fioravanti, "Kelsen, Schmitt e la Tradizione Giuridica dell'Ottocento", en: Maurizio Fioravanti, La Scienza del Diritto Pubblico: Dottrine dello Stato e della Costituzione tra Otto e Novecento, Milano, Giuffrè, 2001, vol. 2, pp. 643645 y 647-650. Consulte también Pier Paolo Portinaro, La Crisi dello Jus Publicum Europaeum, op. cit., pp. 142-144 y Renato Cristi, Carl Schmitt and Authoritarian Liberalism, op. cit., pp. 196-197. En contraposición, Mario Nigro entiende la posición de Carl Schmitt con relación al Estado Administrativo como contraria a este tipo de Estado, pues era el Estado donde ocurría la disolución de la politica, era el Estado impotente que intentaba controlar toda la vida social y económica. Cf. Mario Nigro, "Carl Schmitt e lo Stato Amministrativo", op. cit., pp. 791-793. Nigro está confundiendo, en nuestra opinión, el Estado Administrativo con el Estado Total Cuantitativo, una de sus formas posibles, pero no, como veremos, la única.

39 Para la crítica de Johannes Popitz a la policracia, consulte Hildemarie Dieckmann, Johannes Popitz, op. cit., pp. 132-135 y Lutz-Arwed Bentin, Johannes Popitz und Carl Schmitt, op. cit., 13-18 e $129-131$. 
pública y la pérdida de la capacidad politica del Estado en el esfuerzo de controlar la policracia económica, volvieron incompatible, para Schmitt, la coexistencia entre el parlamentarismo pluralista y el Estado Económico ${ }^{40}$.

Uno de los problemas del Estado Económico alemán, para Schmitt, aún, era la ausencia de una Constitución Económica como Constitución estatal ${ }^{41}$. Dentro de la organización y de la estructura política del Estado no fueron valorizadas estructuras y elementos económicos como tales, además del hecho de que, en el sistema constitucional alemán, el individuo no podia ejercer sus derechos de acuerdo con su condición de sujeto económico. El individuo era citoyen, no producteur, para la Constitución. Para Schmitt, sólo las Constituciones bolchevique y fascista eran verdaderas Constituciones económicas, pues reconocian los nuevos problemas económicos y sociales por parte de la organización estatal, intentando una efectiva supremacía del Estado frente a la economía, en una organización fuerte, sólida y cerrada. En este caso de Estado Económico sin Constitución económica, sólo podría haber dos salidas que solucionarían la cuestión definitivamente: o se retiraría el Estado de la economía, con la neutralización del Estado, o sería creada una Constitución Económica estatal $^{42}$.

Las relaciones entre Estado y economía constituian, para Schmitt, la verdadera raiz de los problemas politicos. Las fórmulas tradicionales, construidas con base en la separación entre Estado y sociedad, daban una noción equivocada de la realidad. La política, interna y externa, era, en gran parte, política económica. La exigencia de no intervención significaba una utopía y una contradicción con relación al propio Estado ${ }^{43}$. De acuerdo con Schmitt, todo Estado adquiere su realidad y fuerza a partir de aquello que en cada época constituye el dominio central de la existencia humana. Como el siglo XIX fue el siglo de predominio de lo económico, y el siglo XX, fue para Schmitt el siglo de la técnica, el Estado no podía renunciar a entender y guiar por sí mismo las circunstancias económicas. Si lo hiciese, tendría que declararse neutral con relación a las verdaderas cuestiones y decisiones politicas, abandonando su pretensión de gobernar ${ }^{44}$.

40 Carl Schmitt, Der Hüter der Verfassung, op. cit., pp. 71-73 y 91-94; Carlo Galli, Genealogia della Politica, op. cit., pp. 650-653 y Renato Cristi, Carl Schmitt and Authoritarian Liberalism, op. cit., p. 182 .

41 Schmitt no consideraba la Constitución de Weimar como una verdadera Constitución Económica, porque ella habría rechazado el sistema de los consejos como principio de la organización estatal. Así, el sistema de consejos, previsto en el artículo 165 de la Constitución, sólo tendría una importancia económica, y no un significado estatal. Para Schmitt, el artículo 165 no hacía de la Constitución de Weimar una Constitución económica y no era posible, también, transformar la Constitución económica del artículo 165 en la Constitución estatal de Alemania. Cf. Carl Schmitt, Der Hüter der Verfassung, op. cit., pp. 97-98.

42 Carl Schmitt, "Wesen und Werden des faschistischen Staates", op. cit., pp. 127-128 y Carl Schmitt, Der Hüter der Verfassung, op. cit., pp. 96-100. Consulte también Lutz-Arwed Bentin, Johannes Popitz und Carl Schmitt, op. cit., pp. 94-99; Pier Paolo Portinaro, La Crisi dello Jus Publicum Europaeum, op. cit., pp. 147-148 y Olivier Beaud, Les Derniers Jours de Weimar, op. cit., pp. 50-52.

43 Carl Schmitt, Der Hüter der Verfassung, op. cit., pp. 80-82.

44 Carl Schmitt, "Der Zeitalter der Neutralisierungen und Entpolitisierungen”, en: Carl Schmitt, Der Begriff des Politischen, op. cit., pp. 83-88. 
La paradoja que Schmitt encontró en el Estado Total se debe a la confusión de los sectores antes distintos de la vida social y de la autoridad estatal. La extensión e intensificación de lo político causó el Estado Total, dotado de un poder inédito que le permitió un control superior a los controles conocidos hasta entonces. Sin embargo, este Estado Total era, al mismo tiempo, un Estado invadido por reivindicaciones y proyectos del cuerpo social, porque con la politización de todos los dominios, la presión sobre el Estado creció. Se multiplicaron los intereses en competencia y que demandaban acción, la política se volvió la lucha de partidos organizados deseando prevalecer unos sobre otros. El Estado Total era, para Schmitt, un Estado débil, amenazado por la disolución. El Estado ya no era soberano, sino un complejo creciente de organismos públicos mal coordinados ${ }^{45}$.

En el caso alemán, Schmitt afirmaba que, con el paso al Estado Total, cerrando la distinción entre Estado y no Estado, era necesario encontrar una nueva organización democrática para Alemania. Esto no había sucedido en 1919, con la Constitución de Weimar, porque la formación de la voluntad estatal estaba en manos de los partidos politicos, que, al desnaturalizar las instituciones constitucionales, crearon un Estado débil que no controlaba los medios tecnológicos. De esta forma, las tareas sociales y económicas de la Constitución de Weimar hicieron crecer la injerencia estatal y, al mismo tiempo, volvieron la administración dependiente de los intereses económicos y sociales organizados. Para Schmitt, la soberanía del Estado alemán se disolvía en la gestión contingente de las relaciones con estos sectores organizados, haciendo del Estado un Estado Total no por su fuerza, sino porque las exigencias de los compromisos entre las diferentes organizaciones sociales obligaron el crecimiento de su intervención, al mismo tiempo que subordinaban su poder. La expansión del Estado de Weimar no era un signo de fuerza, sino de debilidad. El Estado Total de Weimar era un Estado Total Cuantitativo ("Total in einem rein cuantitativen Sinne, in Sinne des blossen Volumens'), además de ser, simultáneamente, un Estado Social, un Estado de Partidos y un Estado Administrativo. Es el pluralismo de Weimar que anuló todas las delimitaciones de lo político y transfirió el monopolio de lo político del Estado a los partidos políticos ${ }^{46}$.

El Estado alemán debía volver a ser un Estado dotado de los instrumentos específicos del poder estatal, como el ejército y la burocracia, además del poder de excepción del artículo 48 de la Constitución de Weimar. De acuerdo con Schmitt, los partidos totales alemanes intentaban evitar el surgimiento de este

45 Carl Schmitt, "Konstruktive Verfassungsprobleme", en: Carl Schmitt, Staat, Grossraum, Nomos, op. cit., p. 59; Paul Hirst, "Carl Schmitt's Decisionism“, op. cit., pp. 18-19 y 23; Jean François Kervégan, Hegel, Carl Schmitt, op. cit., pp. 83-86 y 90-92; Carlo Galli, "Strategie della Totalità: Stato Autoritario, Stato Totale, Totalitarismo, nella Germania degli Anni Trenta", op. cit., pp. 39-40 y William E. Scheuerman, Carl Schmitt, op. cit., pp. 97-99.

46 Carl Schmitt, "Konstruktive Verfassungsprobleme”, op. cit., pp. 56-59; Carl Schmitt, "Starker Staat und gesunde Wirtschaft", en: Carl Schmitt, Staat, Grossraum, Nomos, op. cit., pp. 74-77 y Carl Schmitt, "Weiterentwicklung des totalen Staats in Deutschland", op. cit., p. 213. Consulte también Carl Schmitt, "Legalität und Legitimität", op. cit., pp. 342-343; Lutz-Arwed Bentin, Johannes Popitz und Carl Schmitt, op. cit., pp. 107-110; Vilmos Holczhauser, Konsens und Konflit, op. cit., pp. 170-174; Jean François Kervégan, Hegel, Carl Schmitt, op. cit., pp. 86-88; Olivier Beaud, Les Derniers Jours de Weimar, op. cit., pp. 68-71; Renato Cristi, Carl Schmitt and Authoritarian Liberalism, op. cit., pp. 190-193 y William E. Scheuerman, Carl Schmitt, op. cit., pp. 102-103. 
Estado fuerte, lo opuesto del Estado de Weimar, preocupados solamente en impedirse entre sí la llegada al poder. Este sería el motivo que, en su opinión, explicaría toda la batalla jurídica contra la utilización por el Presidente del Reich de los poderes previstos en el artículo 48 de la Constitución ${ }^{47}$.

La salida, para Carl Schmitt, era la de un Estado Total diferente, contrapuesto al Estado Total Cuantitativo de Weimar: el Estado Total Cualitativo ${ }^{48}$. Este Estado Total Cualitativo es un Estado fuerte, total en el sentido de la calidad y de la energía ("total im Sinne der Qualität und der Energie"), además de autoritario en el ámbito político, para poder decidir sobre la distinción entre amigo y enemigo, y garante de la libertad individual en el ámbito de la economía. Él también debía dominar la tecnología y los medios de comunicación de masas ${ }^{49}$. El principal ejemplo de este tipo de Estado Total para Schmitt era el Estado Fascista, con su superioridad sobre los intereses económicos, de los patrones o de los trabajadores, consiguiendo de ese modo conservar e imponer la dignidad del Estado frente al pluralismo de los intereses económicos. La marca distintiva del Estado Total Cualitativo es la afirmación positiva del poder, porque el Estado es conscientemente ordenado por el concepto de lo politico, sabiendo realizar la distinción entre amigo y enemigo. Este Estado puede salvar, por la decisión política, la esencia de la Constitución de Weimar, depurada de sus contradicciones sobre los derechos fundamentales. Para eso, la restauración de la unidad politica perdida debe ocurrir por la despolitización de las esferas no estatales. El Estado Total Cualitativo subordina la esfera privada, no en el sentido de la politización de la economía, sino para la neutralización de los conflictos en el campo económico. La economía, de esa forma, queda subordinada a las instancias estatales, pero es preservada como ordenamiento social privado y autónomo ${ }^{50}$.

\section{ESTADO FUERTE EN UNA ECONOMÍA LIBRE}

Los intereses sociales y económicos deberían ser confinados a su esfera específica, previniendo su toma de control sobre funciones políticas, lo que debilitaria la unidad política. La salida, para Carl Schmitt, era un Estado fuerte en una economia libre (ein starker Staat in einer freien Wirtschaft). El Estado debia

47 Carl Schmitt, "Starker Staat und gesunde Wirtschaft”, op. cit., pp. 77-79.

48 Para Kervégan, el Estado Total Cuantitativo responde a la lógica económica de expansión de la sociedad civil, mientras que el Estado Total Cualitativo respondería a la lógica politica de la expansión democrática. Para la distinción entre Estado Total Cuantitativo y Estado Total Cualitativo, consulte Vilmos Holczhauser, Konsens und Konflit, op. cit., pp. 174-175; Jean François Kervégan, Hegel, Carl Schmitt, op. cit., pp. 94-95; David Dyzenhaus, Legality and Legitimacy, op. cit., pp. 81-82 y Carlo Galli, "Strategie della Totalità: Stato Autoritario, Stato Totale, Totalitarismo, nella Germania degli Anni Trenta”, op. cit., pp. 39-42.

49 Sobre la necesidad del control de los nuevos medios tecnológicos de control y sugerencia de las masas y de formación de la opinión pública, consulte específicamente Carl Schmitt, "Starker Staat und gesunde Wirtschaft", op. cit., pp. 73-74.

50 Ibid., p. 74 y Carl Schmitt, "Weiterentwicklung des totalen Staats in Deutschland", op. cit., pp. 212-213. Consulte también Carl Schmitt, "Wesen und Werden des faschistischen Staates", op. cit., pp. 125 y 128-129; Hasso Hofmann, Legitimität gegen Legalität, op. cit., pp. 113-116; George SCHWAB, The Challenge of the Exception cit., p. 86; Lutz-Arwed Bentin, Johannes Popitz und Carl Schmitt, op. cit., pp. 110-114; Pier Paolo Portinaro, La Crisi dello Jus Publicum Europaeum, op. cit., pp. 144-145; Jean François Kervégan, Hegel, Carl Schmitt, op. cit., pp. 88-89 y Olivier Beaud, Les Derniers Jours de Weimar, op. cit., pp. 63-66. 
ser el Estado necesario, actuando en favor del interés colectivo y permitiendo la auto-organización y la autonomía económicas, sin interferencia de los partidos politicos. El Estado pluralista debía ser combatido con un proceso de autonomización y despolitización. Lo que debía ser eliminado no era la política en sí, sino una especie de política, la política de partido ${ }^{51}$.

Solamente un Estado fuerte puede retirarse de las esferas no estatales. El Estado neutral es un Estado fuerte, porque separa al Estado de la economía y de la sociedad civil. La neutralización y despolitización de la economía (que son procesos políticos, porque sólo pueden originarse de la decisión política del Estado) necesitan un Estado con liderazgo político, que solamente puede existir si tiene fundamentos plebiscitarios. Schmitt no se oponía al libre mercado, pero entendia que éste solamente puede sobrevivir bajo la égida de este Estado fuerte ${ }^{52}$.

El Estado tenía, para Schmitt, un papel fundamental en los asuntos sociales y económicos. La era del laissez-faire se había acabado, pero el Estado debe, también, saber los limites de su actuación. Schmitt quería una intervención autoritaria en la economía, no la planificación, ni un proyecto de emancipación social. Buscaba reafirmar las condiciones de posibilidad de un comando politico unitario. La economía no es para el Estado, porque existe el riesgo de incorporarlo a los conflictos económicos. La economía debe ser liberal, privada y despolitizada. El poder económico aliado al Estado lo obliga a respetar límites en su actuación en la economía. La intervención del Estado es una amenaza si impone obligaciones sociales. La planificación es aceptada siempre que la clase dominante esté de acuerdo con él. El Estado debe, por lo tanto, alentar a los agentes económicos privados en el sentido de la coordinación económica, reduciendo su intervención directa en la economía al mínimo indispensable. El contexto económico del decisionismo de Schmitt es el de que quien domina la economia determina su curso ${ }^{53}$.

La oposición liberal entre Estado e individuo, de acuerdo con Carl Schmitt, ya no era suficiente en el Estado Total. No había más sentido en la contraposición entre el Estado y el agente económico privado aislado. Era necesario un dominio económico intermedio, entre el Estado y el individuo. Schmitt sugiere la tripartición de la esfera económica, asegurando la esfera económica del Estado

51 Carl Schmitt, Der Hüter der Verfassung, op. cit., pp. 101-111 y Carl Schmitt, "Konstruktive Verfassungsprobleme", op. cit., pp. 60-61. Consulte también Olivier Beaud, Les Derniers Jours de Weimar, op. cit., pp. 52-54 y 58-59.

52 Carl Schmitt, "Legalität und Legitimität", op. cit., pp. 340-341; Carl Schmitt, "Konstruktive Verfassungsprobleme", op. cit., pp. 63-64; Carl Schmitt, "Starker Staat und gesunde Wirtschaft", op. cit., pp. 71, 77 y 81; Lutz-Arwed Bentin, Johannes Popitz und Carl Schmitt, op. cit., pp. 99-101; Pier Paolo Portinaro, La Crisi dello Jus Publicum Europaeum, op. cit., p. 148 y Renato Cristi, Carl Schmitt and Authoritarian Liberalism, op. cit., pp. 188-190. Polanyi destaca que el discurso proponiendo una economía libre bajo un gobierno fuerte fue cada vez más común para sostener las políticas deflacionistas de la década de 1930, así como la propuesta de separación de las esferas política y económica, presente en varios de los autores simpatizantes del fascismo. Consulte Karl Polanyi, The Great Transformation, op. cit., pp. 231 y 241-242.

53 Carl Schmitt, "Konstruktive Verfassungsprobleme", op. cit., pp. 62-63; Ingeborg Maus, "Zur 'Zäsur' von 1933 in der Theorie Carl Schmitts”, op. cit., pp. 104-105; Carlo Galli, Genealogia della Politica, op. cit., pp. 676-677 y William E. Scheuerman, Carl Schmitt, op. cit., pp. 103-104 y $215-$ 216. 
(donde habria un genuino privilegio estatal de ciertas actividades, como los correos), la esfera económica privada pura (de la libre iniciativa y de los emprendimientos individuales) y una esfera intermedia, una esfera pública no estatal ("eine Sphäre, die nichtstaatlich, aber öffentlich ist'), donde predominaría la administración económica autónoma ${ }^{54}$.

Como ejemplos de administración económica autónoma, independiente con relación al Estado de partidos, Schmitt destacaba Reichsbank y la Reichsbahngesellschaft (Compañia de Ferrocarriles). Para satisfacer las exigencias de las reparaciones de guerra, Reichsbank y la Reichsbahngesellschaft habian sido transformados en estructuras neutrales, independientes, en oposición al Estado pluralista de partidos. Estos órganos eran complejos autónomos, diferenciados del resto del gobierno y de la Administración Pública y dotados de amplias garantías contra la influencia de los partidos politicos. En ambos casos, los derechos de soberanía política de Alemania fueron desglosados y fue formado un órgano autónomo que aparecía como independiente y neutral frente al Estado de partidos ${ }^{55}$.

La administración económica autónoma no debe ser confundida con la idea de democracia económica, defendida por los socialdemócratas. De acuerdo con Schmitt, la democracia económica tenía base en una mezcla entre economía y política, buscando adquirir poder económico en el Estado por medios de poder político y, consecuentemente, aumentando su poder político con su mayor poderío económico. La administración económica autónoma, a su vez, exige la distinción entre Estado y economía. Ella es una esfera económica que pertenece al interés público y no puede ser separada de él. El Estado solamente surge en condiciones específicas, no ambiguas, para realizar sus tareas necesarias. La administración económica autónoma es un dominio económico público no estatal ("einer öffentlichen, aber nicht staatlichen Wirtschaft'), que puede ser organizado y administrado de forma neutral y técnica por los propios agentes económicos ${ }^{56}$.

Estas concepciones de Schmitt fueron criticadas por los juristas socialdemócratas Otto Kirchheimer y Franz Neumann. Kirchheimer destacaba que la lucha por el poder económico sucedió en la esfera de la distribución. Un Parlamento con representación de los trabajadores, como el de la República de Weimar, no satisfacía más al poder económico, que intentaba eliminar el poder político parlamentario eliminando los vínculos entre la mecánica política y el poder económico, o sea, aislando la esfera de la distribución contra la influencia de los cambios políticos. La neutralización de áreas específicas de la economía tenía, por lo tanto, el objetivo de aislarlas de la influencia política de los órganos de representación popular 57 .

De acuerdo con Franz Neumann, la idea de la no intervención del Estado fue aceptada por los sectores reaccionarios europeos cuando el Estado se volvió

54 Carl Schmitt, "Starker Staat und gesunde Wirtschaft”, op. cit., pp. 79-80.

55 Carl Schmitt, Der Hüter der Verfassung, op. cit., pp. 106-107.

56 Carl Schmitt, "Starker Staat und gesunde Wirtschaft”, op. cit., pp. 80-81. Consulte también Carl Schmitt, Die geistesgeschichtliche Lage des heutigen Parlamentarismus, op. cit., nota 1, p. 14, y p. 33; Lutz-Arwed Bentin, Johannes Popitz und Carl Schmitt, op. cit., pp. 112-113 y Renato Cristi, Carl Schmitt and Authoritarian Liberalism, op. cit., pp. 197-199.

57 Otto Kirchheimer, "Weimar - und was dann? Analyse einer Verfassung”, op. cit., pp. 42-46. 
democrático. Estos sectores no admitían que el Estado interfiriera en el poder económico. El fascismo, para Neumann, surgió justamente de la necesidad de los poseedores del poder económico de un Estado fuerte que no estuviese bajo el control del pueblo, o sea, el fascismo fue una reacción contraria a los intentos de democratización de la economia ${ }^{58}$.

En su discurso "Estado Fuerte y Economía Sana" ("Starker Staat und gesunde Wirtschaft'), de 6 de noviembre de 1932, en Langnamverein (una asociación de industriales alemanes), Schmitt afirmó que el pueblo alemán debería, además y por encima de las divisiones partidarias, buscar su unidad política por medio de un Estado fuerte. Pero para instituir el Estado fuerte, independiente de los partidos políticos, no se podría correr el riesgo de falsas reformas. Habría, por lo tanto, la necesidad de una nueva Constitución59: "Nosotros necesitamos, en primer lugar, de un Estado fuerte que sea capaz de actuar y que esté listo para sus grandes tareas. Cuando lo tengamos, podremos entonces crear nuevos arreglos, nuevas instituciones, nuevas constituciones" 60.

El Estado Total fue, de ese modo, el último intento de Schmitt en los años 1930 de aprovechar el monopolio decisorio del Estado sobre lo político como forma de garantizar la unidad política por sobre el pluralismo de los intereses económicos y sociales. El liberalismo político fue descartado por Schmitt, pero no el liberalismo económico. El modelo económico schmittiano buscaba reforzar el capital, liberándolo del Estado Social. La decisión de Carl Schmitt, según Ingeborg Maus, fue una decisión contra el statu quo político-jurídico, pero a favor del statu quo económico. La despolitización de la economía y de la sociedad, por medio del Estado Total Cualitativo, buscaba privilegiar los intereses económicos dominantes contra la democracia pluralista, el Estado Social y los derechos sociales garantizados en la Constitución de Weimar ${ }^{61}$.

\section{BIBLIOGRAFÍA}

ANSCHÜTZ, Gerhard, Die Verfassung des Deutschen Reichs vom 11. August 1919, reimpr., 14 ed., Aalen, Scientia Verlag, 1987 (fecha de publicación original: 1933)

58 Franz Neumann, "Economics and Politics in the Twentieth Century", en: Franz Neumann, The Democratic and the Authoritarian State, op. cit., pp. 264-265.

59 Carl Schmitt, "Konstruktive Verfassungsprobleme”, op. cit., pp. 61-62 y Carl Schmitt, "Starker Staat und gesunde Wirtschaft", op. cit., pp. 83-85. Consulte también Renato Cristi, Carl Schmitt and Authoritarian Liberalism, op. cit., pp. 29-35 y 193-199. Para Ingeborg Maus, este discurso de Schmitt habría adelantado la simbiosis entre la gran industria y el nazismo, que sucedería a partir del año siguiente. Cf. Ingeborg Maus, "Existierten zwei Nationalsozialismen?", en: Ingeborg Maus, Rechtstheorie und Politische Theorie im Industriekapitalismus, op. cit., pp. 8789.

60 Carl Schmitt, "Starker Staat und gesunde Wirtschaft”, op. cit., p. 83.

61 Lutz-Arwed Bentin, Johannes Popitz und Carl Schmitt, op. cit., pp. 116-119; Ingeborg Maus, Bürgerliche Rechtstheorie und Faschismus, op. cit., pp. 126 y 152-155; Heinrich Meier, Die Lehre Carl Schmitts, op. cit., pp. 210-213 y William E. Scheuerman, Carl Schmitt, op. cit., pp. 101-102. Consulte también el análisis de Polanyi, que destacó el papel del fascismo en la revitalización del sistema económico capitalista con la extinción de la democracia. Cf. Karl Polanyi, The Great Transformation, op. cit., pp. 243-245. 
BEAUD, Olivier, Les Derniers Jours de Weimar: Carl Schmitt face à l'Avènement du Nazisme, Paris, Descartes \& Cie., 1997

BENTIN, Lutz-Arwed, Johannes Popitz und Carl Schmitt: Zur wirtschaftlichen Theorie des totalen Staates in Deutschland, München, C. H. Beck, 1972

BLOMEYER, Peter, Der Notstand in den letzten Jahren von Weimar, Berlin, Duncker \& Humblot, 1999

CRISTI, Renato, "Le Restaurant Cosmopolite - Libéralisme, Démocratie et Catholicisme chez Carl Schmitt", en CRISTI, Renato, Le Libéralisme Conservateur: Trois Essais sur Schmitt, Hayek et Hegel, Paris, Éditions Kimé, 1993, pp. 15-50

CRISTI, Renato, Carl Schmitt and Authoritarian Liberalism: Strong State, Free Economy, Cardiff, University of Wales Press, 1998

DIECKMANN, Hildemarie, Johannes Popitz: Entwicklung und Wirksamkeit in der Zeit der Weimarer Republik, Berlin-Dahlen, Colloquium Verlag, 1960

DYZENHAUS, David, Legality and Legitimacy: Carl Schmitt, Hans Kelsen and Hermann Heller in Weimar, Oxford/New York, Oxford University Press, 1999

FELDMAN, Gerald D., The Great Disorder: Politics, Economics, and Society in the German Inflation, 1914-1924, Oxford/New York, Oxford University Press, 1997

FIORAVANTI, Maurizio, “Kelsen, Schmitt e la Tradizione Giuridica dell'Ottocento”, en FIORAVANTI, Maurizio, La Scienza del Diritto Pubblico: Dottrine dello Stato e della Costituzione tra Otto e Novecento, Milano, Giuffrè, 2001, vol. 2, pp. 605-656

GALlI, Carlo, Genealogia della Politica: Carl Schmitt e la Crisi del Pensiero Politico Moderno, Bologna, Il Mulino, 1996

GALLI, Carlo, "Strategie della Totalità: Stato Autoritario, Stato Totale, Totalitarismo, nella Germania degli Anni Trenta", Filosofia Politica, ano XI, n ${ }^{\circ}$, 1997, pp. 27-62

GÓMEZ ORFANEL, Germán, Excepción y Normalidad en el Pensamiento de Carl Schmitt, Madrid, Centro de Estudios Constitucionales, 1986

GRAU, Richard, "Die Diktaturgewalt des Reichspräsidenten" en ANSCHÜTZ, Gerhard \& THOMA, Richard (coords.), Handbuch des Deutschen Staatsrechts, reimpr., Tübingen, J. C. B. Mohr (Paul Siebeck), 1998, vol. 2, pp. 274-295 e $732-$ 733 (fecha de publicación original: 1932).

GUSY, Christoph, Die Weimarer Reichsverfassung, Tübingen, J.C.B. Mohr (Paul Siebeck), 1997

HECKEL, Johannes, "Diktatur, Notverordnungsrecht, Verfassungsnotstand", Archiv des öffentlichen Rechts, vol. 22, 1932, pp. 257-338

HELLER, Hermann, "Der Begriff des Gesetzes in der Reichsverfassung", en HELLER, Hermann, Gesammelte Schriften, 2 ed., Tübingen, J.C.B. Mohr (Paul Siebeck), 1992, vol. 2, pp. 203-247 (fecha de publicación original: 1927).

HIRST, Paul, "Carl Schmitt's Decisionism", Telos no 72, Summer 1987, pp. 15-26

HOFMANN, Hasso, Legitimität gegen Legalität: Der Weg der politischen Philosophie Carl Schmitts, 4 ed., Berlin, Duncker \& Humblot, 2002

HOLCZHAUSER, Vilmos, Konsens und Konflit: Die Begriffe des Politischen bei Carl Schmitt, Berlin, Duncker \& Humblot, 1990 
HUBER, Ernst Rudolf, "Zur Lehre vom Verfassungsnotstand in der Staatstheorie der Weimarer Zeit", en SCHNEIDER, Hans (edit.), Im Dienst an Recht und Staat: Festschrift für Werner Weber zum 70. Geburstag, Berlin, Duncker \& Humblot, 1974, pp. 31-52

KERVÉGAN, Jean François, Hegel, Carl Schmitt: Le Politique entre Spéculation et Positivité, Paris, PUF, 1992

KIRCHHEIMER, Otto, "Weimar - und was dann? Analyse einer Verfassung", en KIRCHHEIMER, Otto, Politik und Verfassung, Frankfurt am Main, Suhrkamp, 1964, pp. 9-56 (fecha de publicación original: 1930).

KURZ, Achim, Demokratische Diktatur? Auslegung und Handhabung des Artikels 48 der Weimarer Verfassung 1919-25, Berlin, Duncker \& Humblot, 1992

MAUS, Ingeborg, Bürgerliche Rechtstheorie und Faschismus: Zur sozialen Funktion und aktuellen Wirkung der Theorie Carl Schmitts, 2 ed., München, Wilhelm Fink Verlag, 1980

MAUS, Ingeborg, "Existierten zwei Nationalsozialismen?", en MAUS, Ingeborg, Rechtstheorie und Politische Theorie im Industriekapitalismus, München, Wilhelm Fink Verlag, 1986, pp. 83-92

MAUS, Ingeborg, “Zur 'Zäsur' von 1933 in der Theorie Carl Schmitts”, en MAUS, Ingeborg, Rechtstheorie und Politische Theorie im Industriekapitalismus, München, Wilhelm Fink Verlag, 1986, pp. 93-110

McCORMICK, John P., Carl Schmitt's Critique of Liberalism: Against Politics as Technology, Cambridge, Cambridge University Press, 1999

MEIER, Heinrich, Die Lehre Carl Schmitts: Vier Kapitel zur Unterscheidung Politischer Theologie und Politischer Philosophie, Stuttgart/Weimar, Metzler, 1994

MOMMSEN, Wolfgang, Max Weber et la Politique Allemande, 1890-1920, Paris, PUF, 1985

NEUMANN, Franz, "Libertà di Coalizione e Costituzione: La Posizione dei Sindacati nel Sistema Costituzionale", en NEUMANN, Franz, Il Diritto del Lavoro fra Democrazia e Dittatura, Bologna, Il Mulino, 1983, pp. 141-284 (fecha de publicación original: 1932).

NEUMANN, Franz, "The Change in the Function of Law in Modern Society", en NEUMANN, Franz, The Democratic and the Authoritarian State: Essays in Political and Legal Theory, Glencoe, The Free Press, 1957, pp. 22-68 (fecha de publicación original: 1937).

NEUMANN, Franz, "Economics and Politics in the Twentieth Century", en NEUMANN, Franz, The Democratic and the Authoritarian State: Essays in Political and Legal Theory, Glencoe, The Free Press, 1957, pp. 257-269 (fecha de publicación original: 1951).

NIGRO, Mario, "Carl Schmitt e lo Stato Amministrativo", Rivista Trimestrale di Diritto e Procedura Civile, Anno XL, n. 3, septiembre 1986, pp. 769-794

POLANYI, Karl, The Great Transformation: The Political and Economic Origins of Our Time, 2 ed., Boston, Beacon Press, 2001 (fecha de publicación original: 1944). PORTINARO, Pier Paolo, La Crisi dello Jus Publicum Europaeum: Saggio su Carl Schmitt, Milano, Edizioni di Comunità, 1982 
RICHTER, Ludwig, “Die Vorgeschichte des Art. 48 der Weimarer Reichsverfassung", Der Staat, vol. 37, 1998, pp. 1-26

RICHTER, Ludwig, "Reichspräsident und Ausnahmegewalt: Die Genese des Artikels 48 in den Beratungen der Weimarer Nationalversammlung", Der Staat, vol. 37, 1998, pp. 221-247

ROSSITER, Clinton, Constitutional Dictatorship: Crisis Government in the Modern Democracies, reimpr., New Brunswick/London, Transaction Publishers, 2002 (fecha de publicación original: 1948).

SCHEUERMAN, William E., Carl Schmitt: The End of Law, Lanham/New York/Oxford, Rowman \& Littlefield Publishers, 1999

SCHEUERMAN, William E., "The Economic State of Emergency", Cardozo Law Review vol. 21, 2000, pp. 1869-1894

SCHMITT, Carl, "Reichspräsident und Weimarer Verfassung", en SCHMITT, Carl, Staat, Grossraum, Nomos: Arbeiten aus den Jahren 1916-1969, Berlin, Duncker \& Humblot, 1995, pp. 24-32 (fecha de publicación original: 1925).

SCHMITT, Carl, Die geistesgeschichtliche Lage des heutigen Parlamentarismus, 8 ed., Berlin, Duncker \& Humblot, 1996 (fecha de publicación original: 1923)

SCHMITT, Carl, "Die Diktatur des Reichspräsidenten nach Artikel 48 der Weimarer Verfassung", en SCHMITT, Carl, Die Diktatur: Von den Anfängen des modernen Souveränitätsgedankens bis zum proletarischen Klassenkampf, 6 ed., Berlin, Duncker \& Humblot, 1994, pp. 211-257 (fecha de publicación original: 1924).

SCHMITT, Carl, Der Begriff des Politischen: Text von 1932 mit einem Vorwort und drei Corollarien, 6 ed., Berlin, Duncker \& Humblot, 1996 (fecha de publicación original: 1927).

SCHMITT, Carl, Verfassungslehre, 8 ed., Berlin, Duncker \& Humblot, 1993 (fecha de publicación original: 1928)

SCHMITT, Carl, "Der bürgerliche Rechtsstaat", en SCHMITT, Carl, Staat, Grossraum, Nomos: Arbeiten aus den Jahren 1916-1969, Berlin, Duncker \& Humblot, 1995, pp. 44-54 (fecha de publicación original: 1928).

SCHMITT, Carl, "Der Zeitalter der Neutralisierungen und Entpolitisierungen", en SCHMITT, Carl, Der Begriff des Politischen: Text von 1932 mit einem Vorwort und drei Corollarien, 6 ed., Berlin, Duncker \& Humblot, 1996, pp. 79-95 (fecha de publicación original: 1929).

SCHMITT, Carl, "Wesen und Werden des faschistischen Staates", en SCHMITT, Carl, Positionen und Begriffe im Kampf mit Weimar-Genf-Versailles, 1923-1939, 3 ed., Berlin, Duncker \& Humblot, 1994, pp. 124-130 (fecha de publicación original: 1929).

SCHMITT, Carl, Der Hüter der Verfassung, 4 ed., Berlin, Duncker \& Humblot, 1996 (fecha de publicación original: 1931).

SCHMITT, Carl, "Legalität und Legitimität", en SCHMITT, Carl, Verfassungsrechtliche Aufsätze aus den Jahren 1924-1954: Materialien zu einer Verfassungslehre, 3 ed., Berlin, Duncker \& Humblot, 1985, pp. 263-350 (fecha de publicación original: 1932). 
SCHMITT, Carl, "Konstruktive Verfassungsprobleme", en SCHMITT, Carl, Staat, Grossraum, Nomos: Arbeiten aus den Jahren 1916-1969, Berlin, Duncker \& Humblot, 1995, pp. 55-70 (fecha de publicación original: 1932).

SCHMITT, Carl, "Starker Staat und gesunde Wirtschaft", en SCHMITT, Carl, Staat, Grossraum, Nomos: Arbeiten aus den Jahren 1916-1969, Berlin, Duncker \& Humblot, 1995, pp. 71-91 (fecha de publicación original: 1932).

SCHMITT, Carl, "Weiterentwicklung des totalen Staats in Deutschland", en SCHMITT, Carl, Positionen und Begriffe im Kampf mit Weimar-Genf-Versailles, 1923-1939, 3 ed., Berlin, Duncker \& Humblot, 1994, pp. 211-216 (fecha de publicación original: 1933).

SORDI, Bernardo, Tra Weimar e Vienna: Amministrazione Pubblica e Teoria Giuridica nel Primo Dopoguerra, Milano, Giuffrè, 1987

STOLLEIS, Michael, Geschichte des öffentlichen Rechts in Deutschland, vol. 3: Staats- und Verwaltungsrechtswissenschaft in Republik und Diktatur, 1914-1945, München, Verlag C.H. Beck, 1999

THOMA, Richard, "Das Reich als Demokratie" in ANSCHÜTZ, Gerhard \& THOMA, Richard (coords.), Handbuch des Deutschen Staatsrechts, reimpr., Tübingen, J. C. B. Mohr (Paul Siebeck), 1998, vol. 1, pp. 186-200 (fecha de publicación original: 1930).

TINGSTÉN, Herbert, Les Pleins Pouvoirs: L'Expansion des Pouvoirs Gouvernementaux Pendant et Après la Grande Guerre, Paris, Librairie Stock (Publications du Fonds Descartes), 1934

WATKINS, Frederick Mundell, The Failure of Constitutional Emergency Powers under the German Republic, Cambridge (Ms.), Harvard University Press, 1939

Enviado el (Submission Date): 24/08/2019

Aceptado el (Acceptance Date): 4/10/2019 